\title{
False-Negative Serum Cryptococcal Antigen Lateral Flow Immunoassay Result for a Patient with Disseminated Cryptococcal Disease
}

This article was published in the following Dove Press journal: Infection and Drug Resistance

\author{
Yuqiao $X u^{1,2}$ \\ Wenying $\mathrm{Xia}$ (iD) ${ }^{1,2}$ \\ Fang $\mathrm{Ni}^{1,2}$ \\ 'Department of Laboratory Medicine, \\ Jiangsu Province Hospital and Nanjing \\ Medical University First Affiliated \\ Hospital, Nanjing, People's Republic of \\ China; ${ }^{2}$ National Key Clinical \\ Department of Laboratory Medicine, \\ Nanjing, People's Republic of China
}

\begin{abstract}
Cryptococcus neoformans (C. neoformans) is an opportunistic fungal pathogen to humans, which can be acquired from environmental sources. Its most important virulence factor is its polysaccharide capsule, which can be used for diagnostic tests that identify the cryptococcal antigen (CrAg). The CrAg lateral flow assay (LFA) is a dipstick immunochromatographic assay with high sensitivity and specificity; however, several false-negative cases have been reported. Here, we present a case of a false-negative serum CrAg LFA, in which the blood culture from a matched sample was positive for C. neoformans, thus demonstrating the postzone phenomenon.
\end{abstract}

Keywords: Cryptococcus neoformans, lateral flow immunoassay, postzone phenomenon

\section{Introduction}

Cryptococcosis is a fungal infection caused primarily by Cryptococcus neoformans and $C$. gattii. ${ }^{1}$ C. neoformans is an opportunistic fungal pathogen, with its critical virulence factor being a polysaccharide capsule located externally to the cell wall. Polysaccharide capsules can be released into the environment, where they are termed exopolysaccharides.

Cryptococcosis is definitively diagnosed from pathogen cultures in Sabouraud dextrose agar. However, the culture results typically take several days because of its slow growth. ${ }^{2}$ Thus, rapid and reliable diagnostic methods are necessary because early diagnosis can decrease the mortality from cryptococcosis. Serological methods for detecting CrAg, including the latex agglutination (LA) test, enzyme immunoassay (EIA), and lateral flow immunoassay (LFA), have been used in clinical practice to diagnose cryptococcosis. The LFA is useful because it provides stable results at room temperature with minimal required laboratory equipment. Compared with the EIA and LA test, the LFA shows equivalent or superior overall sensitivity. In 2011, the World Health Organization recommended the CrAg LFA test as an effective method for diagnosing cryptococcosis $;^{3}$ however, it occasionally yields false-negative results.

This case report describes a false-negative result from a serum CrAg LFA in a patient with disseminated cryptococcal disease, whose blood culture tested positive for $C$. neoformans. This case highlights the need for better knowledge of this situation and discussion of its possible causes.
Correspondence: Wenying Xia; Fang Ni Department of Laboratory Medicine, liangsu Province Hospital and Nanjing Medical University First Affiliated Hospital, Guangzhou Street No. 300, 210029, People's Republic of China Tel $+8625-6830-6287$

Fax $+8625-8372-4440$

Email xiawenying21106891@163.com;

|38|3972378@|63.com
Infection and Drug Resistance 2020:13 2877-288I

mit your manuscript

(c) (i) $82020 \mathrm{Xu}$ et al. This work is published and licensed by Dove Medical Press Limited. The full terms of this license are available at https://www.dovepress.com/terms.php cC. ${ }_{\text {BY NC }}$ and incorporate the Creative Commons Attribution - Non Commercial (unported, v3.0) License (http://creativecommons.org/licenses/by-nc/3.0/). By accessing the work you hereby accept the Terms. Non-commercial uses of the work are permitted without any further permission from Dove Medical Press Limited, provided the work is properly attributed. For permission for commercial use of this work, please see paragraphs 4.2 and 5 of our Terms (https://www.dovepress.com/terms.php). 


\section{Case Presentation}

A 79-year-old woman presented to our infection division with hyperpyrexia. She had nephrotic syndrome and diabetes and had been treated with traditional Chinese medicine, hormones and insulin for a long time. Two weeks prior (day 0), she was referred to a local hospital for fever with shivering. A chest computed tomography (CT) scan revealed inflammatory lesions in both lungs. She was treated with cefazolin and levofloxacin, which were changed to imipenem combined with moxifloxacin on day 7 after her blood culture results indicated an Escherichia coli infection; however, her symptoms persisted after 1 week of treatment.

The patient was subsequently admitted to our infection division for further treatment. At the time of admission (day 15), her physical examination results were temperature, $38.2^{\circ} \mathrm{C}$; blood pressure, $124 / 56 \mathrm{mmHg}$; heart rate, 99 beats/ minute; and respiratory rate, 18 breaths/minute. The patient was lethargic and dispirited. Her laboratory examination results were white blood cells, $36,300 / \mu \mathrm{L}$ with $92.2 \%$ neutrophils; C-reactive protein, $105 \mu \mathrm{g} / \mathrm{mL}$; procalcitonin, 0.5205 $\mathrm{ng} / \mathrm{mL}$; and interleukin, $60.042 \mathrm{ng} / \mathrm{mL}$. During her hospitalization, her temperature continued to increase to $40^{\circ} \mathrm{C}$ (day 21). Her blood, sputum and cerebral spinal fluid (CSF) specimens were sent to our department for microbiological examinations. The CrAg LFA yielded a negative result for the serum (IMMY Inc., Norman, OK, USA) and a positive result for the CSF. India ink staining and CSF culture results were both negative. Parenteral voriconazole was initiated as empiric treatment pending diagnostic testing (day 21).

After 4 days and 16 hours (day 24) of blood culturing using an automated blood culture system (BACTEC FX,BD Becton, Dickinson and Company), pathogens were detected microscopically from two aerobic blood culture bottles. Microscopically, the pathogens were gram-positive, budding, round conidia, suggesting Cryptococcus spp. India ink staining of the fluid in the positive blood culture bottles revealed the pathogenic capsules. Microscopically, the pathogens appeared as rounded cells with thick halos (Figure 1A). The strains were isolated from Sabouraud dextrose agar after 24 hours of aerobic incubation and appeared as beige mucoid yeast colonies (Figure 1B). Identification using the VITEK 2 compact automated system (BioMerieux, France) yielded a positive result for $C$. neoformans. With confirmation of disseminated cryptococcosis, the initial negative serum LFA test result was questioned. Per the manufacturer's instructions, we serially diluted the serum and processed it using the CrAg LFA test kit. Increasing dilutions showed that the 1:5 dilution was negative, 1:10 and 1:20 were weakly positive, and 1:40 was positive.

Antimicrobial susceptibility tests were performed via the microdilution broth method using ATB FUNGUS 3 (BioMerieux). In vitro antimicrobial susceptibility testing showed that the minimal inhibitory concentrations for the C. neoformans were 5-fluorouracil (5-FC) $4 \mu \mathrm{g} / \mathrm{mL}$, amphotericin B (AMB) $0.5 \mu \mathrm{g} / \mathrm{mL}$, fluconazole (FLU) $1 \mu \mathrm{g} / \mathrm{mL}$, voriconazole (VOR) $0.125 \mu \mathrm{g} / \mathrm{mL}$, and itraconazole (ITR) $0.06 \mu \mathrm{g} / \mathrm{mL}$. As per previous studies, the epidemiological cutoff values for $C$. neoformans were $8 \mu \mathrm{g} / \mathrm{mL}$ for 5 -FC and FLU, $0.25 \mu \mathrm{g} / \mathrm{mL}$ for ITR and VOR, and $1 \mu \mathrm{g} / \mathrm{mL}$ for AMB. ${ }^{4-6}$ Thus, the patient's antibiotics were changed to AMB plus 5-FC on day 26. After 1 week of treatment, her infection was controlled, and she was transferred to a local hospital for rehabilitation.

\section{Discussion}

Cryptococcosis is definitively diagnosed from pathogen cultures in Sabouraud dextrose agar. However, C. neoformans may take several days to culture because of its slow growth. Additionally, the number of pathogens as well as previous use of antifungal agents may influence
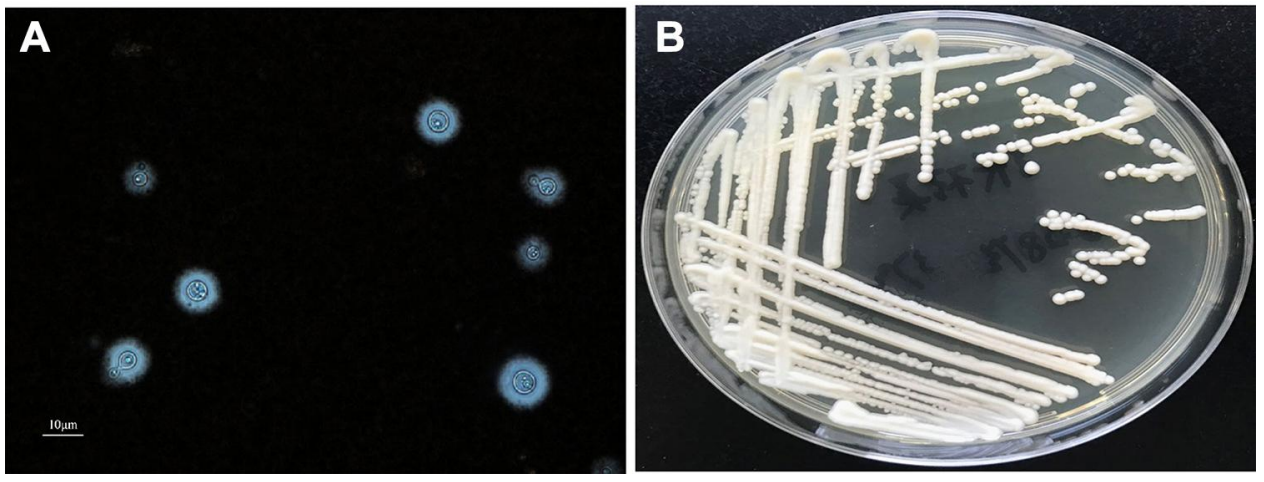

Figure I (A) Morphology of C. neoformans in blood culture bottle by Indian ink staining $(\times 400)$. (B) Colony morphology of $C$. neoformans on Sabouraud dextrose agar. 
the culture results. ${ }^{3}$ Cryptococcal meningitis $(\mathrm{CM})$ can be diagnosed by microscopy of fresh CSF using India ink staining, which has $100 \%$ specificity but only $50 \%$ sensitivity depending on cell titers and capsule production. ${ }^{7}$ In the early stages, India ink staining results may appear normal, as with the patient in this case. The CrAg, a component of the glucuronoxylomannan polysaccharide capsule, which is soluble and detectable in serum or body fluids as a marker of infection, is used for timely and sensitive diagnoses of cryptococcosis. ${ }^{8,9}$ Several serological methods for CrAg detection, such as LA, EIA and LFA tests, have been developed. In the LA test, particles are coated with specific antibodies and agglutinated $\mathrm{CrAg}$ in the sera of infected patients. ${ }^{10}$ LA sensitivity in serum ranges from $83 \%-97 \%$, and its specificity ranges from $93 \%-100 \%,{ }^{11}$ but the test is manual, subjective and timeconsuming. The EIA is a direct, microplate-based, immunoenzymatic sandwich assay, with $100 \%$ sensitivity and $98 \%$ specificity. ${ }^{11}$ The LFA is widely used as a rapid and cheap method for diagnosing cryptococcosis, with both
$100 \%$ sensitivity and specificity. ${ }^{12}$ The LFA test requires minimal laboratory equipment; thus, it can be easily performed in many laboratories.

In our patient, the C. neoformans blood culture and the positive LFA result for the CSF revealed that the patient had disseminated cryptococcosis. C. neoformans first infects the lungs, then spreads to the central nervous system (CNS) through the blood. The patient had not yet shown obvious symptoms of CNS infection, indicating that the $\mathrm{CM}$ was in the early stage of infection. The culture and India ink staining of the CSF were negative; the $\mathrm{CrAg}$ detection in CSF is significant for the diagnosis of CM.

Although the patient was diagnosed with disseminated cryptococcosis, the serum LFA test result was negative. Mahajan et al reported a case of unencapsulated C. neoformans with a negative CrAg. ${ }^{13}$ India ink staining of the fluid in the positive blood culture bottles showed that the $C$. neoformans appeared as rounded cells with thick halos, indicating that the patient was not infected by an unencapsulated or weakly capsulated strain. Another

Table I Reports of False-Negative Cryptococcal Antigen Lateral Flow Assay in Recent Years

\begin{tabular}{|c|c|c|c|c|c|c|c|c|c|c|c|}
\hline Year & Country & Age & Gender & Comorbidities & $\begin{array}{l}\text { Clinical } \\
\text { Presentation }\end{array}$ & Specimen & Culture & Bacteria & Treat & $\begin{array}{l}\text { Clinical } \\
\text { Outcome }\end{array}$ & $\begin{array}{l}\text { Ref. } \\
\text { No. }\end{array}$ \\
\hline 2014 & $\begin{array}{l}\text { South } \\
\text { Africa }\end{array}$ & 59 & $\begin{array}{l}\text { Not } \\
\text { Found }\end{array}$ & AIDS & Not Found & CSF & Positive & C. neoformans & Not Found & Not Found & [16] \\
\hline 2014 & $\begin{array}{l}\text { South } \\
\text { Africa }\end{array}$ & 59 & $\begin{array}{l}\text { Not } \\
\text { Found }\end{array}$ & AIDS & Not Found & CSF & Positive & C. neoformans & Not Found & Not Found & \\
\hline 2014 & $\begin{array}{l}\text { South } \\
\text { Africa }\end{array}$ & 59 & $\begin{array}{l}\text { Not } \\
\text { Found }\end{array}$ & AIDS & Not Found & CSF & Positive & C. neoformans & Not Found & Not Found & \\
\hline 2018 & USA & 42 & M & AIDS & $\begin{array}{l}\text { Weakness, } \\
\text { cough, } \\
\text { headache }\end{array}$ & CSF & Positive & C. neoformans & $\begin{array}{l}\text { Amphotericin B } \\
\text { and Flucytosine }\end{array}$ & Recover & [15] \\
\hline 2018 & USA & 49 & M & AIDS & $\begin{array}{l}\text { Lethargy, } \\
\text { febrile, } \\
\text { tachycardic }\end{array}$ & CSF & $\begin{array}{l}\text { Not } \\
\text { Found }\end{array}$ & C. neoformans & $\begin{array}{l}\text { Amphotericin } \\
\text { B and high-dose } \\
\text { fluconazole }\end{array}$ & Not Found & [17] \\
\hline 2016 & USA & 63 & M & No & $\begin{array}{l}\text { Gait } \\
\text { dysfunction, } \\
\text { headache }\end{array}$ & CSF & Positive & C. neoformans & $\begin{array}{l}\text { Amphotericin } \\
B \text { and } \\
\text { flucytosine }\end{array}$ & Not Found & [13] \\
\hline 2018 & Australia & $\begin{array}{l}\text { Not } \\
\text { Found }\end{array}$ & $\begin{array}{l}\text { Not } \\
\text { Found }\end{array}$ & Not Found & Not Found & Serum & $\begin{array}{l}\text { Sputa } \\
\text { culture } \\
\text { was } \\
\text { positive }\end{array}$ & C. gattii & Not Found & Not Found & [14] \\
\hline 2018 & Australia & $\begin{array}{l}\text { Not } \\
\text { Found }\end{array}$ & $\begin{array}{l}\text { Not } \\
\text { Found }\end{array}$ & Not Found & Not Found & Serum & $\begin{array}{l}\text { Sputa } \\
\text { culture } \\
\text { was } \\
\text { positive }\end{array}$ & C. gattii & Not Found & Not Found & \\
\hline
\end{tabular}


case report described a false-negative serum CrAg result via LFA in an HIV-positive patient, as demonstrated by a blood culture from a matched sample that was positive for Cryptococcus spp. (Table 1). ${ }^{14}$ The serum CrAg test may have been negative owing to the postzone effect. Unfortunately, the culture specimen was not stored, so the CrAg LFA could not be titrated to evaluate this hypothesis. Therefore, the serum was diluted, and LFA tests were repeated to resolve the discrepancy. After diluting the serum ten times, the LFA result was weakly positive. The false-negative LFA result occurred due to the postzone phenomenon, also known as the "hook" effect. When the antigen concentration is too high, excess antibodies will prevent cross-linking and interfere with antibody-antigen precipitation, leading to false-negative results.

Reports of false-negative results due to the postzone phenomenon are uncommon. Our review included 8 cases of falsenegative CrAg LFAs described in five reports (Table 1). Six were in the CSF and in HIV-infected patients. ${ }^{15-18}$ However, the only specimens tested were CSF. A retrospective study of patients with culture-confirmed $\mathrm{CM}$ showed that the $\mathrm{CrAg}$ LFA had $100 \%$ sensitivity in the serum. ${ }^{19}$ Testing serum for $\mathrm{CrAg}$ is recommended, especially for patients who cannot undergo an immediate lumbar puncture or when lumbar puncture is contraindicated.

Cryptococcosis treatment is complex. "Practice Guidelines for the Management of Cryptococcal Disease" was first published by the Infectious Diseases Society of America (IDSA) in $2000 .^{20}$ According to these guidelines, a three-part regimen of "induction-consolidation-maintenance" is recommended for immunocompromised patients. This includes AMB plus 5-FC for 2 weeks, FLU for 8-10 weeks, then a lower dose of FLU for 6-12 months. In this case, the patient was treated according to these guidelines, and the infection was controlled well.

\section{Conclusion}

This is the first reported case of the postzone phenomenon occurring on an LFA from an HIV-negative patient who had disseminated cryptococcosis caused by C. neoformans. When disseminated cryptococcosis is highly suspected, but the CrAg LFA is negative, a serial dilution must be performed to rule out a false-negative test due to the postzone phenomenon. Clinicians should always be cautious when laboratory test results do not fit the strong clinical suspicion.

\section{Ethics and Consent Statement}

Because of the patient's unstable state of consciousness, written informed consent was provided by the patient's relative to allow the case details to be published, and our study was approved by the Ethics Committee at Jiangsu Province Hospital.

\section{Funding}

This study was supported by the Key Laboratory for Laboratory Medicine of Jiangsu Province of China, No. ZDXKB2016005.

\section{Disclosure}

The authors declare that there have no conflicts of interest in this work.

\section{References}

1. Pappas PG, Alexander BD, Andes DR, et al. Invasive fungal infections among organ transplant recipients: results of the transplant-associated infection surveillance network (Transnet). Clin Infect Dis. 2010;50(8):1101-1111. doi:10.1086/651262

2. Nawrot U, Kowalska-Krochmal B, Sulik-Tyszka B, et al. Evaluation of blood culture media for the detection of fungi. Eur J Clin Microbiol Infect Dis. 2015;34(1):161-167. doi:10.1007/s10096-014-2218-4

3. Zhou Y, Lin PC, Ye JR, et al. The performance of serum cryptococcal capsular polysaccharide antigen test, histopathology and culture of the lung tissue for diagnosis of pulmonary cryptococcosis in patients without HIV infection. Infect Drug Resist. 2018;11:2483-2490. doi:10.2147/IDR.S178391

4. Espinel-Ingroff A, Aller AI, Canton E, et al. Cryptococcus neoformans-Cryptococcus gattii species complex: an international study of wild-type susceptibility endpoint distributions and epidemiological cutoff values for fluconazole, itraconazole, posaconazole, and voriconazole. Antimicrob Agents Chemother. 2012;56(11):5898-5906. doi:10.1128/AAC.01115-12

5. Espinel-Ingroff A, Chowdhary A, Cuenca-Estrella M, et al. Cryptococcus neoformans-Cryptococcus gattii species complex: an international study of wild-type susceptibility endpoint distributions and epidemiological cutoff values for amphotericin B and flucytosine. Antimicrob Agents Chemother. 2012;56(6):3107-3113. doi:10.1128/AAC.06252-11

6. Espinel-Ingroff A, Chowdhary A, Gonzalez GM, et al. Multicenter study of isavuconazole MIC distributions and epidemiological cutoff values for the Cryptococcus neoformans-Cryptococcus gattii species complex using the CLSI M27-A3 broth microdilution method. Antimicrob Agents Chemother. 2015;59(1):666-668. doi:10.1128/AAC.04055-14

7. Makadzange AT, McHugh G. New approaches to the diagnosis and treatment of cryptococcal meningitis. Semin Neurol. 2014;34 (1):47-60. doi:10.1055/s-0034-1372342

8. Saha DC, Xess I, Biswas A, Bhowmik DM, Padma MV. Detection of Cryptococcus by conventional, serological and molecular methods. J Med Microbiol. 2009;58(Pt 8):1098-1105. doi:10.1099/jmm.0.007328-0

9. Temfack E, Boyer-Chammard T, Lawrence D, et al. New insights into cryptococcus spp. biology and cryptococcal meningitis. Curr Neurol Neurosci Rep. 2019;19(10):81. doi:10.1007/s11910-019-0993-0

10. Bloomfield N, Gordon MA, Elmendorf DF Jr. Detection of cryptococcus neoformans antigen in body fluids by latex particle agglutination. Proc Soc Exp Biol Med. 1963;114:64-67. doi:10.3181/00379727-114-28586 
11. Vidal JE, Boulware DR. Lateral flow assay for cryptococcal antigen: an important advance to improve the continuum of HIV care and reduce cryptococcal meningitis-related mortality. Rev Inst Med Trop Sao Paulo. 2015;57(Suppl 19):38-45. doi:10.1590/S0036-46652015000700008

12. Caceres DH, Zuluaga A, Tabares AM, Chiller T, Gonzalez A, Gomez BL. Evaluation of a cryptococcal antigen lateral flow assay in serum and cerebrospinal fluid for rapid diagnosis of cryptococcosis in Colombia. Rev Inst Med Trop Sao Paulo. 2017;59:e76. doi:10.1590/s1678-9946201759076

13. Mahajan KR, Roberts AL, Curtis MT, Fortuna D, Dharia R, Sheehan L. Diagnostic challenges of cryptococcus neoformans in an immunocompetent individual masquerading as chronic hydrocephalus. Case Rep Neurol Med. 2016;2016:7381943.

14. Borges M, Araujo Filho JA, Soares RBA, Vidal JE, Turchi MD. Falsenegative result of serum cryptococcal antigen lateral flow assay in an HIV-infected patient with culture-proven cryptococcaemia. Med Mycol Case Rep. 2019;26:64-66. doi:10.1016/j.mmcr.2019.10.009

15. Yadava SK, Fazili T. Postzone phenomenon resulting in a false-negative cerebral spinal fluid cryptococcal antigen lateral flow assay. AIDS. 2019;33(6):1099-1100. doi:10.1097/QAD.0000000000002157
16. Lourens A, Jarvis JN, Meintjes G, Samuel CM. Rapid diagnosis of cryptococcal meningitis by use of lateral flow assay on cerebrospinal fluid samples: influence of the high-dose "hook" effect. J Clin Microbiol. 2014;52(12):4172-4175. doi:10.1128/JCM.01683-14

17. Kojima N, Chimombo M, Kahn DG. False-negative cryptococcal antigen test due to the postzone phenomenon. AIDS. 2018;32 (9):1201-1202. doi:10.1097/QAD.0000000000001805

18. Currie BP, Freundlich LF, Soto MA, Casadevall A. False-negative cerebrospinal fluid cryptococcal latex agglutination tests for patients with culture-positive cryptococcal meningitis. J Clin Microbiol. 1993;31(9):2519-2522. doi:10.1128/JCM.31.9.2519-2522.1993

19. Jarvis JN, Percival A, Bauman S, et al. Evaluation of a novel point-of-care cryptococcal antigen test on serum, plasma, and urine from patients with HIV-associated cryptococcal meningitis. Clin Infect Dis. 2011;53(10):1019-1023. doi:10.1093/cid/cir613

20. Saag MS, Graybill RJ, Larsen RA, et al. Practice guidelines for the management of cryptococcal disease. Infectious Diseases Society of America. Clin Infect Dis. 2000;30(4):710-718. doi:10.1086/313757
Infection and Drug Resistance

\section{Publish your work in this journal}

Infection and Drug Resistance is an international, peer-reviewed openaccess journal that focuses on the optimal treatment of infection (bacterial, fungal and viral) and the development and institution of preventive strategies to minimize the development and spread of resistance. The journal is specifically concerned with the epidemiology of
Dovepress

antibiotic resistance and the mechanisms of resistance development and diffusion in both hospitals and the community. The manuscript management system is completely online and includes a very quick and fair peerreview system, which is all easy to use. Visit http://www.dovepress.com/ testimonials.php to read real quotes from published authors. 